\title{
EMPTY CITY SPACES. PRACTICES OF UNSEEN
}

\author{
ANNA GAŃKO \\ Institute of Polish Culture, University of Warsaw \\ Krakowskie Przedmieście 26/28, 00-001 Warszawa, Poland \\ E-mail address: and.ganko@gmail.com \\ ORCID: https://orcid.org/0000-0001-8664-455X
}

Aim. The aim of this paper is to depict the ambivalent status of bygone city spaces - defined and identified by things that were there before - that are perceived as empty. Because they are obsolete, they do not function in accordance with their primarily intended use they become devastated and ruined, they create a specific environment for various actions that in organised and structured spaces remain hidden and invisible.

Method. The study is a reflection on social functioning of city spaces perceived as abandoned - their ambivalent status in context of practices connected with urban space. A significant part of the article is a polemic with Kroessler's metaphor city as a palimpsest.

Result and Conclusions. The analysis shows the ambivalent status of urban spaces that are perceived as empty. They, by definition, consist of a specific kind of absence and simultaneously paradoxically they make some aspects of urban space functioning visible.

Key words: Bygone places, urban space, palimpsest, landscape, ruins

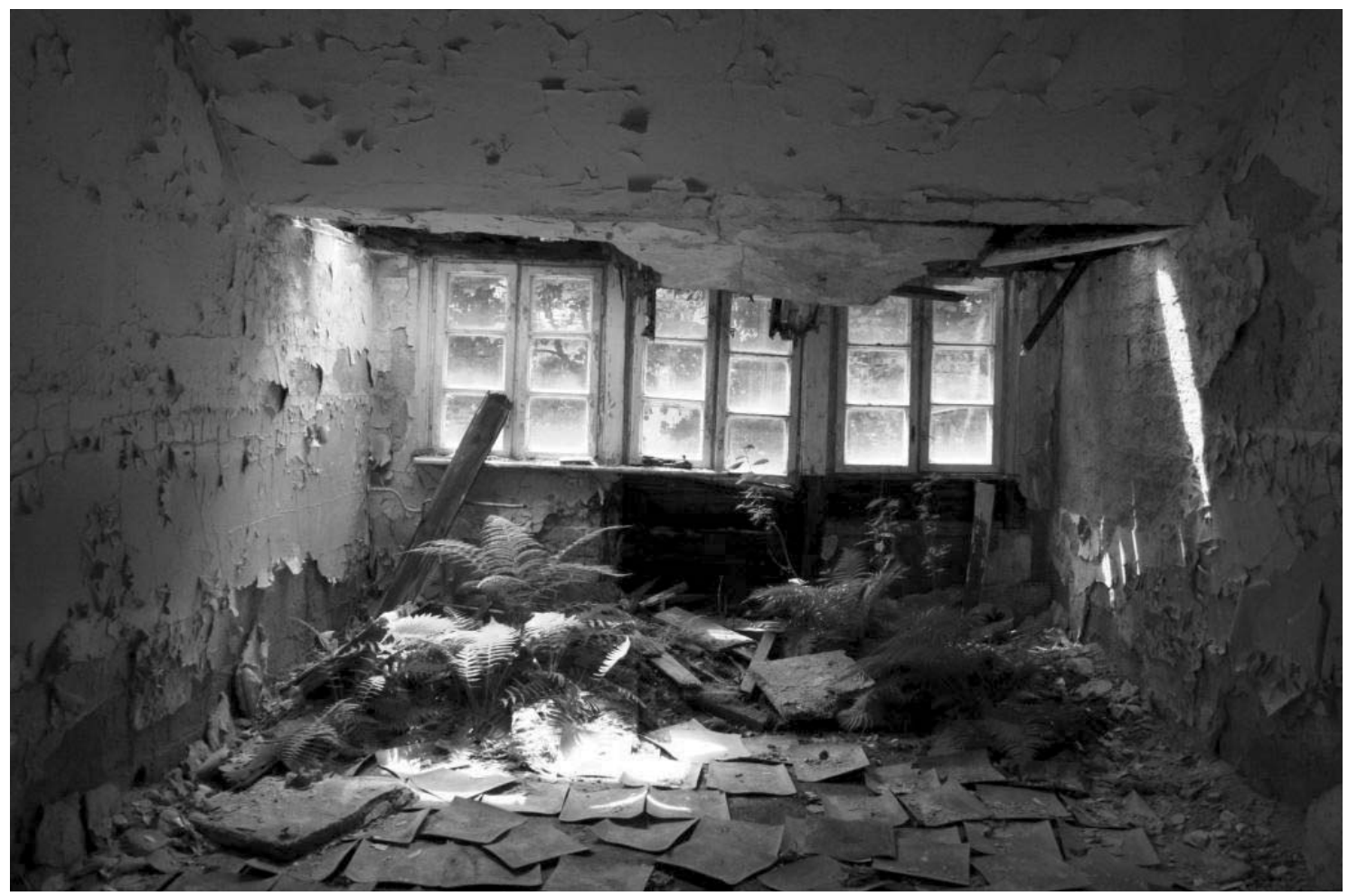

Figure 1.

Abandoned soviet hospital in Legnica. Plants take over the place (own photo). 


\section{NEVER EMPTY CITY}

Bygone places - as places defined and identified by what were there before Bare by their definition referring to something beyond their actual function or form. They can be easily described by the sentence: „here it was”. They are in a way perceived (conceptualised) as marks of their previous state. Therefore, the category of bygone places can include a wide variety of particular places starting from memorial sites (Assmann, 2009) and ending in contaminated landscapes (Pollack, 2014). In an urban context bygone places frequently are preserved as monuments or museums, where their historic potential is exploited, but where modern bygone places are concerned - like obsolete factories, former train stations, uninhabited tenement houses - very often they come under processes of ruination, devastation and fouling. These are claimed and perceived as abandoned.

What is more such areas are usually excluded from everyday people's practices - they are separated from commonly used urban places, mostly because of the dangers they threaten. Such separation appears in different ways: very often it's just a high fence whose function is to keep anyone away from the spot or it is out of sight of peoples everyday practices - it's the place avoided by most people - they will not walk there, they do not make plans for spending time there - they do not think about using it as they use any other urban space. Because of this, ruined and devastated bygone places are excluded from everyday practices and often regarded as empty. They appear as blank areas on a densely built-in city map. They are uncharted - useless, dangerous - areas to avoid.

They seem to be physically erased from the structured and maintained urban spaces. In perspective of such phenomena, urban space can be regarded as similar to a palimpsest - it is an analogy popularised by Jeffrey A. Kroessler. He defines a palimpsest after a $17^{\text {th }}$ dictionary definition as "paper, parchment, or other writing material designed to be reusable after any writing on it has been erased" (Kroessler, 2015, p. 3).

In the following analogy of the city as a palimpsest, it will be composed of various elements that are constantly changing, being rebuilt and replaced by others. According to architectural historian Anthony Robins urban spaces can be seen as consisting of layers - city space exists not only in its present form but simultaneously in its previous shapes (Kroessler, p. 4). This indicates one of the most important features of urban space (and space in general) - it is never finished. It is impossible to find a final form in the city - it is constantly developing and changing. It is always in process as a temporal product of human actions in a twofold sense: top-down strategies like planning, designing, managing and overseeing, as well as everyday spontaneous activities.

The second aspect reveals the point where J. A. Kroessler's analogy is insufficient. Describing city space as a palimpsest - a re-wrtitten manuscript - indicates only some of its features, without drawing the whole context. It 
describes it as something basically visual and containing a meaning, possible to be read and understood (even though sometimes that meaning is not obvious). Even though the visual aspect of organisation of city space very often comes to the foreground, it shades a more primal way of the existence of urban space - being used and experienced - and as such as being perceived and understood.

Urban space is a place for living and as a specific environment of various human activities in the first place is a human's surroundings perceived not only by sight but also by any other sense. It can be seen as a specific urban landscape, "the world as it is known to those who dwell therein, who inhabit its places and journey along the paths connecting them" (Ingold, 2000, p. 193). Thus, dwelling and specifically using the urban space is the basis of recognising its elements, understanding their functions and affordances (Gibson, 1979). So the matter of understanding is not only that what people see about the urban space, just as they can see the form of written words but how they use it and what is possible for them to think as useful about experienced space - simply what they can do with or in the space and what they think they can do.

But analysing J. A. Kroessler's analogy one more specific feature of urban space, especially important for the topic briefly presented in that paper bygone places - can be found: they are never empty. Even though it might be easy to indicate areas perceived as abandoned, useless and even described as city wastelands, they are always included in complexity of various relations.

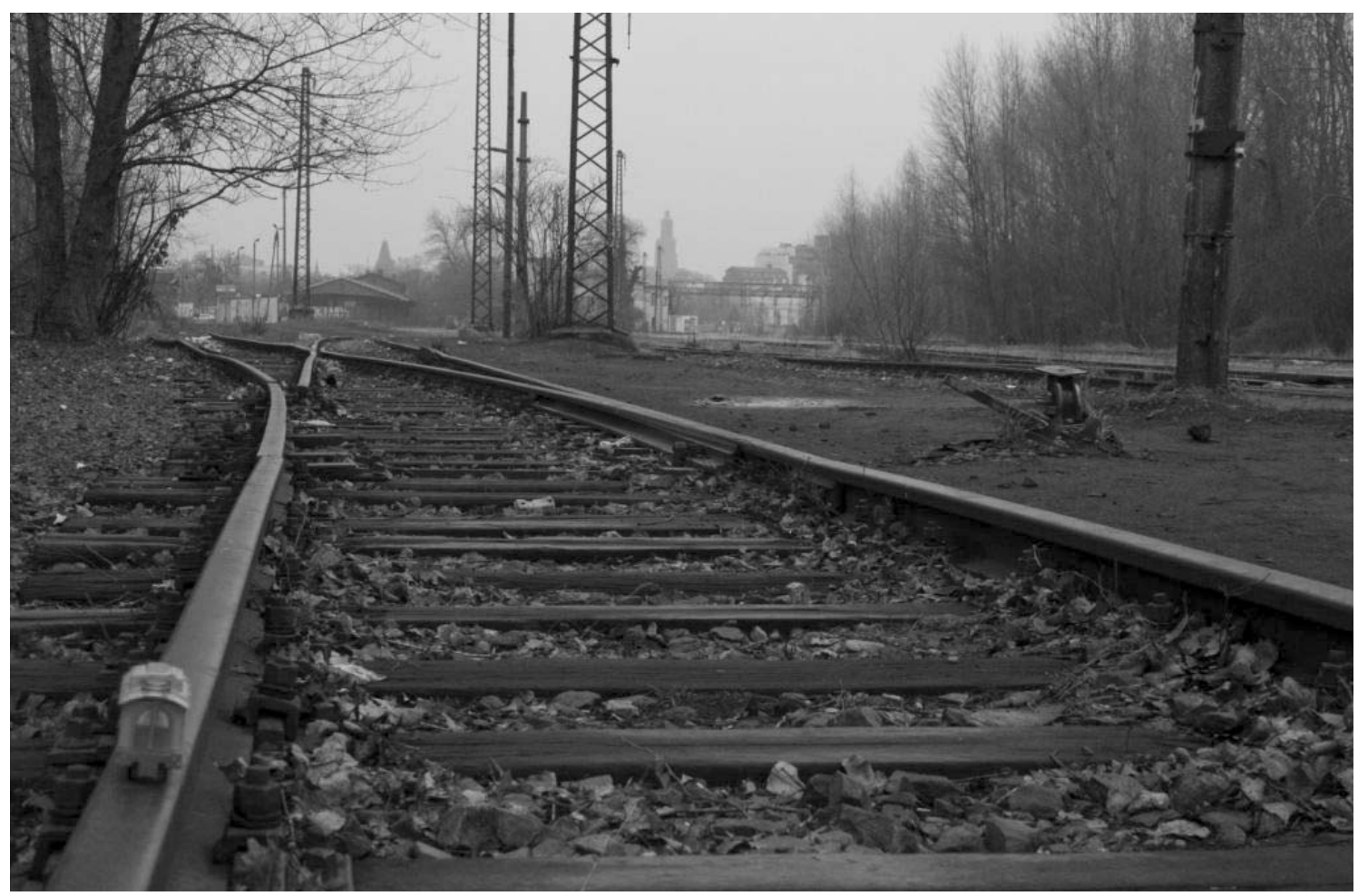

Figure 2.

Past and presence. Nonfunctioning train station in Wrocław (own photo). 


\section{City CAUGHT IN THE MIDDLE}

If we follow idea of urban space constructed of several layers, connected with its history including people's everyday actions, abandoned spaces are deprived of the most external one - one that is most obvious for actual users and current usages. They strip down city space from the newest layer - they manifest those elements that remain hidden in other urban areas, where they are shaded by current aspects and components. It is related to the material form of the city, its architectural growth. City structure develops, new forms are replacing, adapting or absorbing old ones. Bygone, abandoned places seem to remain the same. It gives the opportunity of experiencing the historic part of the city - especially when newest history is concerned. It also shows social and economic changes that have been made during city development. Carefully gazing at city map with abandoned places marked and gazing at ruins themselves can be simultaneously watching temporal effects of the non-ending process of city change.

In this context bygone places appear as hovering between the past: their previous form, and function and the future: as a potential for future uses. They seem to be caught in the middle. They can be described as transitional spaces when they broaden Tomasz Rakowski's (2008) term of transitional objects. When organised and maintained city spaces pretend to be in their final form, pretend to be finished, city ruins manifest their temporal character and thus they reveal dynamic status of urban space elements. Modern ruins, thus modern bygone places as well, enable constant reflexion on modernity at the interface between various levels of meanings and concerning it through a compilation of that which is real and which is imagined, what is past and what is to come, what is recognisable and what cannot be recognised at first glance (Nieszczerzewska, 2018, p. 22)

However, urban space should be recognised not only as a configuration of buildings, material objects and connections between them but first of all it consists of human practices, shared ways of living and inhabiting spaces resulting in regulatory systems, social strategies and everyday tactics. Thence it is possible for abandoned places - excluded from everyday commonly shared practices and often passed over in official management - to become the scene of actions that in organised and structured spaces remain hidden and invisible.

Constitutive for bygone places' existence is a specific kind of absence. In the first place it is absence of their previous function because of their obsolescence and lack of their primary form because of progressive decay. They conspicuously are not what they used to be. Secondly, bygone places' absence manifests itself in the domain of human everyday activities - as long as they are not places to use but places to avoid. Because they appear on the basis of absence it makes them show things and actions that cannot fit into official regulatory systems and city strategies. Because they are stripped of the most obviously given, ordered and controlled layer of city space they can be areas to show what remains shaded elsewhere. "Ruins confound the normative spacings of 
things, practices and people. They open up possibilities for regulated urban bodies to escape their shackles in expressive pursuits and sensual experience, foreground alternative aesthetics about where and how things should be situated, and transgress boundaries between outside and inside, and between human and non-human spaces" (Edensor, 2005a, p. 18).

So what remains unseen in the ordered and organised parts of the city and simultaneously can be observed in abandoned areas? First, the most obvious thing, are the inner sides of buildings and space: intestines of the buildings - wires, pipes, concrete blocks. "The pipes, wiring and tubes spring out from their confinement behind walls and under floors and skeletal girders and joists emerge as plaster and wood rots and peels off. Drainage channels and ventilation shafts appear, and phone lines and electricity wires break out from their imprisonment, often in a seemingly exuberant display. Catalysed by contact with moisture, temperatures and non-human life, the latent energies within matter are expended in this escape" (Edensor, 2005b, p. 318). Except of the inner side of buildings and objects non-human and non-simply-material factors start to act. Weather: wind, sun, temperature, humidity present themselves as active parts of the city space form. Moreover plants, animals, worms are "waiting in the wings" (Edensor, 2015, p. 52) to take advantage of human absence.

But this human absence, even though it is strictly limited and officially claimed, is not totally implemented. To be precise: it is a place where one should not be, but which does not mean that it is a place where none is. Because of that it creates a convenient environment for those who can benefit from its ambivalent character and want to remain unseen., just like illegal inhabitants or adventure seekers. They can be observed by traces and marks of their activities left behind: trash, trodden paths or provisional arrangements of the space. "The material traces of people are everywhere, object-presences which conjure up the absence of those who were, wielded, utilized and consumed them. Most evidently, the bodies of absent workers are summoned up by the intact or shredded remnants of articles of clothing." (Edensor, 2005b, p. 328). Tim Edensor writes about those who were users of the place in the past. Their activities: particular actions, everyday habits, objects used by them are taking part in creating the space - its form and meaning. Their active bodies leave marks on the space. In the same way present users, even though they try to remain unseen leave their marks. Those traces are somehow side effects of their actions. They are not given to be seen - in a city - palimpsest metaphor they are markings, that are not intentionally given to be read.

But not all marks in the abandoned spaces are of this type. Some of them are not only marks but explicit signs. They are left by those who are using the abandoned places' context to lead specific play with the space and with the absence. Even though they do not want to present themselves personally they wish to mark their presence. What is more, some of them presume other visitors of that place and invite them to some kind of game based on the dialectic of dichotomies: between presence and absence, between what is visible and what is hidden. It is possible by recognising such places as empty and simul- 
taneously preparing them to be visited. So that every other visitor is able to leave his own signs and lead specific dialogue with invisible others through the space. Rules of that game directly what the essence of urban spaces is: not only what can or cannot be seen there, but what can be found and used. Those other components: not only seen but specifically using as the basis of recognition and understanding of urban space.

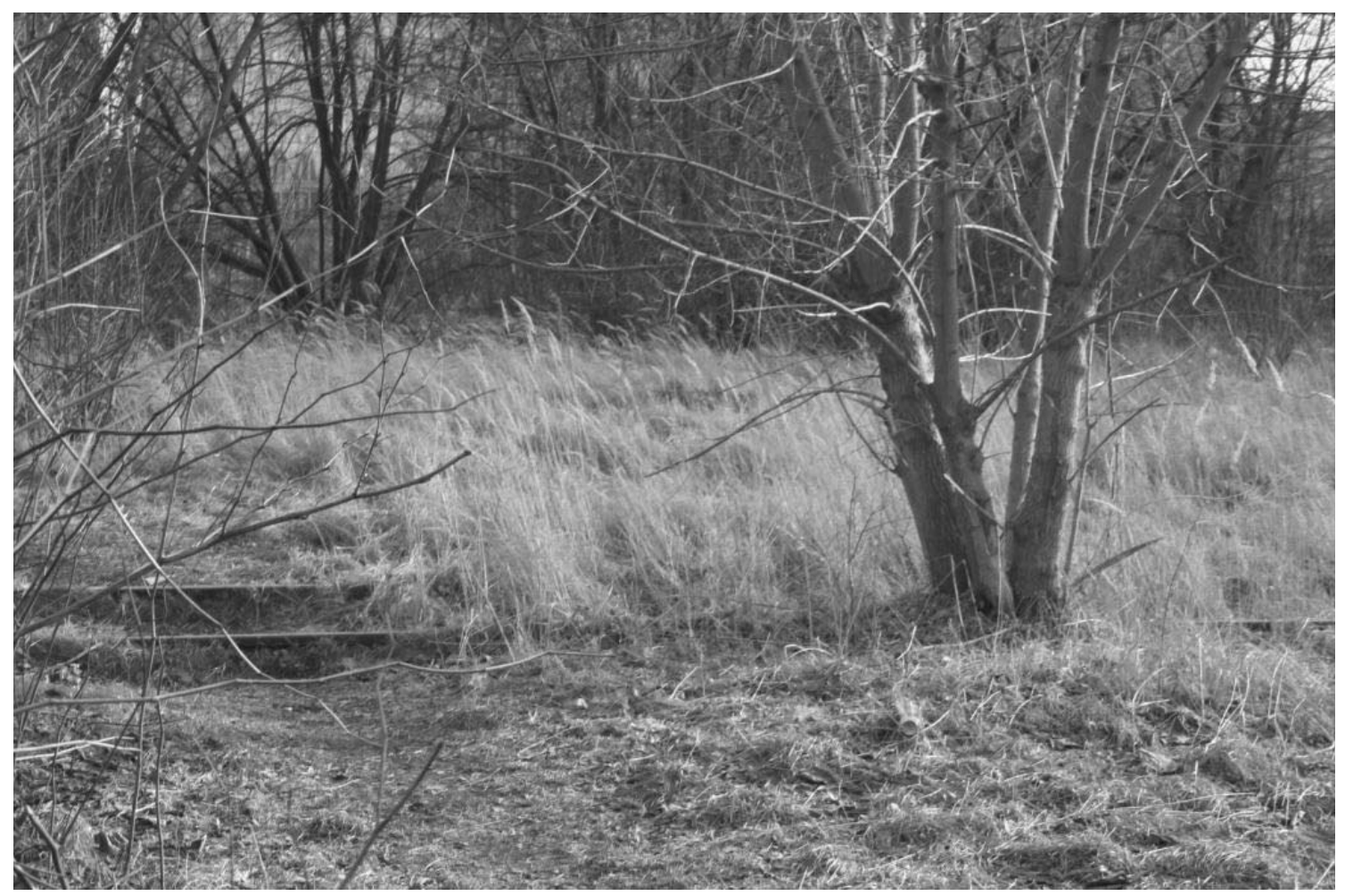

Figure 3.

A path in overgrown area of former Main Train Station in Warsaw (own photo).

\section{CITY AS A LABYRINTH}

J. A. Kroessler claims that a "palimpsest is an ideal metaphor for the living city - a writing tablet on which layer after layer of messages was inscribed, always legible yet never completely erasing what was written before" (Kroessler, 2015, p. 11). I would argue that moveable labyrinth is a better metaphor. It is constantly changing - one set of elements is erased and replaced by other just like in a rewritten manuscript. But a crucial difference is that the city is not given to look at but to use and recognising and understanding it is not based on mere configuration of signs but on practices. Sometimes elements of city space are given to be read, but sometimes they are explicitly a path trodden by someone who was there before. 


\section{REFERENCES}

1. Assmann, A. (2009). Przestrzenie pamięci. Formy i przemiany pamięci kulturowej [Spaces od memory. Forms and transformations of cultural memory]. In: M. Saryusz-Wolska (Ed.), Pamięć zbiorowa i kulturowa. Wspótczesna perspektywa niemiecka (pp. 101-142). Kraków: Universitas.

2. Edensor, T. (2005a). Industrial Ruins: Aesthetics, Materiality and Memory. Oxford: Berg.

3. Edensor, T. (2005b). Waste Matter - the debris of industrial ruins and the disordering of the material world. Journal of Material Culture, 10 (3), 311-332.

4. Edensor T. (2015). Suddenly Obsolete: The Sensations and Affects of the Ruin. In N. Brownsword (Ed.). Topographies of the Obsolete: Site Reflections 2015 (pp. 50-56). Buckingham: Topographies of Obsolete.

5. Gibson, J. J. (1979). The Ecological Approach to Visual Perception, Hillsdale: LawrenceErlbaum Associates.

6. Ingold, T. (2000). The Perception of the Environment. Essays on livelihood, dwelling and skill. London and New York: Routledge.

7. Kroessler, J. A. (2015). The city as Palimpsest. CUNY Academic Works. Retrieved from: https:// academicworks.cuny.edu/jj_pubs/42.

8. Nieszczerzewska, M. (2018). Ruinologie. Kontekstualizacje pozostałości architektury. Poznań: Wydawnictwo Naukowe Wydziału Nauk Społecznych.

9. Pollack, M. (2014). Skażone krajobrazy [Contaminated landscapes]. Wołowiec: Wydawnictwo Czarne.

10. Rakowski, T. (2008). Przemiany, przesunięcia, przedmioty przejściowe. Antropologia rzeczy [Transformations, shifts, transitory objects. The anthropology of things as a methodological challenge]. Kultura Wspótczesna, 2/2008, 55-72. 